\title{
Molecular characterisation of Armillaria species from Zimbabwe
}

\author{
Eddie MWENJE ${ }^{1}$, Brenda D. WINGFIELD ${ }^{2}$, Martin P. A. COETZEE ${ }^{2}$ and Michael J. WINGFIELD ${ }^{2}$ \\ ${ }^{1}$ Department of Applied Biology and Biochemistry, National University of Science and Technology, P.O. Box AC 939 Ascot, \\ Bulawayo, Zimbabwe. \\ ${ }^{2}$ Department of Genetics, Tree Pathology Co-operative Programme (TPCP), Forestry and Agricultural Biotechnology Institute \\ (FABI), University of Pretoria, Pretoria, 0002, South Africa. \\ E-mail: brenda.wingfield@fabi.up.ac.za
}

Received 22 August 2002; accepted 21 January 2003.

\begin{abstract}
Armillaria species are amongst the most important pathogens of trees and have a world-wide distribution. In recent years, the taxonomy of Northern Hemisphere Armillaria spp. has been extensively treated, but those occurring in Africa are poorly known. Previously, isolates of Armillaria from Zimbabwe have been grouped based on morphology and biochemical tests. In this study, six isolates representing the three previously characterized groups of Armillaria spp. occurring in Zimbabwe were analysed using DNA-based techniques. Three distinct clusters emerged from both PCR-RFLP and analysis of sequence data for the IGS-1 rRNA operon. The three groups corresponded to those previously identified based on morphology and biochemical tests. Differences in IGS-1 sequences strongly suggest that the Zimbabwean groups represent three distinct taxa. Isolates belonging to Group I, previously assumed to be to A. heimii, were similar to those identified as A. fuscipes from South Africa and La Reunion. Group II isolates resided in a clade apart from all other isolates and appear to represent $A$. heimii. The remaining isolates residing in Group III clustered with isolates from Zambia and Cameroon. These are different from $A$. heimii and $A$. fuscipes and apparently represent an undescribed taxon.
\end{abstract}

\section{INTRODUCTION}

The genus Armillaria has a world-wide distribution and includes some of the most important root pathogens of forest trees and fruit crops. The taxonomy of Armillaria has presented problems for many years due to the assumption that $A$. mellea is a single polymorphic species. This has lead to the grouping of many of the currently recognized Armillaria spp. within A. mellea s. lat. The re-classification of the genus, especially in Europe, where several species are known to occur, is based mainly on mating tests (Korhonen 1978). As a result, at least five biological and morphologically distinct species, previously thought to be A. mellea, have been described in Europe (Korhonen 1978, Pegler 2000). Application of mating tests have further led to the recognition of at least nine biological species in North America (Anderson \& Ullrich 1979, Anderson 1986, Volk \& Burdsall 1995) and at least ten biological species in Asia (Ota et al. 1998). Several species of Armillaria are known to occur in Australia and New Zealand and these have been reasonably well studied (Pegler et al. 1978, Kile \& Watling 1981, 1983, 1988).
However, very little is known regarding the taxonomy of species of Armillaria in Africa.

In one of the early studies aimed at identifying Armillaria spp. from Africa, Pegler (1977) recognized two species, $A$. heimii and $A$. mellea. Subsequent to this study, it was generally assumed that $A$. heimii is the major species in Africa (Mohammed et al. 1994). A number of studies on Armillaria in Africa have followed and based on morphological variation in culture, physiological, biochemical and somatic compatibility tests, four groups have been recognized. These groups are thought to represent A. mellea (African), $A$. heimii and two groups for which names have not been provided (Mohammed et al. 1994, AbomoNdongo \& Guillaumin 1997, Chillali et al. 1997, Mwenje \& Ride 1997). In addition to these, Coetzee et al. (2000) have recently shown that A. fuscipes, previously thought to be synonymous with $A$. heimii, is a distinct and common species in South African pine plantations.

A. heimii has been presumed to be the predominant species in Zimbabwe (Mohammed et al. 1994). Using pectic isozymes, especially pectic lyase patterns, 
Table 1. Armillaria isolates from Zimbabwe and South Africa used in IGS-1 analysis.

\begin{tabular}{llll}
\hline $\begin{array}{l}\text { Group*/ } \\
\text { species }\end{array}$ & Isolate no. & Country/area of origin & Host \\
\hline Group I & CMW10165 & Zimbabwe, Chimanimani & $\begin{array}{l}\text { GenBank } \\
\text { accession no. }\end{array}$ \\
Group I & CMW4874 & Zimbabwe, Stapleford persica & AF489482 \\
Group II & CWM4455 & Zimbabwe, Eastern & Aracaria cunninghamii \\
& & Highlands Estates & Camellia sinensis \\
Group II & CMW4456 & Zimbabwe, Stapleford & Brachystegia utilis \\
Group III & CMW10115 & Zimbabwe, Harare & Acia albida \\
Group III & CMW10116 & Zimbabwe, Harare & Newtonia buchananii \\
A. fuscipes & CMW2717 & South Africa, Sabie & P. elliottii \\
A. fuscipes & CMW2740 & South Africa, Entabeni \\
A. fuscipes & CMW3167 & South Africa, Sabie & P. elliottii \\
A. heimii & CMW3173 & Zambia, Dola Hill & Tectona grandis \\
A. heimii & CWM3152 & Cameroon, Western Highlands & Unknown \\
A. fuscipes & CMW3164 & La Reunion, Saint-Denis & Pelargonium asperum \\
A. heimii & CMW3955 & Zimbabwe, Harare & Acacia xanthophloea \\
\hline
\end{tabular}

* Groups represent those defined by Mwenje \& Ride (1996).

Mwenje \& Ride (1996) showed that Armillaria isolates from Zimbabwe reside in three biochemically distinct groups (Groups I-III). Isozyme analysis of other enzymes such as beta-1,3 glucanases, non-specific esterases and putative suberinases further supported separation of the Zimbabwean isolates into these three groups (Mwenje \& Ride 1996). In addition to these studies, Mwenje \& Ride (1996) found that the isolates from Zimbabwe could be differentiated into the three groups based on their colony morphology, characteristics of their rhizomorphs and morphology of basidiocarps produced in vitro (Mwenje \& Ride 1996). Isolates representing the three Zimbabwean Armillaria groups have been shown to differ in their pathogenicity on cassava (Monihot esculenta). Group III isolates were the most pathogenic and also have the widest distribution in the country (Mwenje, Ride \& Pearce 1998). The differences in morphology, isozymes and pathogenicity among the various Zimbabwean groups suggested that they could represent distinct species.

In recent years Armillaria root rot has increased in importance in fruit and pine seed orchards in the eastern highlands of Zimbabwe. While death caused by Armillaria in Zimbabwe varies between 1 and $25 \%$ in commercial plantations, higher figures $(60 \%)$ have been reported in fruit orchards, especially in Prunus spp. (Mwenje et al. 1998). Although some information is available on the distribution and pathogenicity of Armillaria in Zimbabwe (Mwenje et al. 1998), the identity of the species of Armillaria remains unknown.

The recent discovery of $A$. fuscipes in South Africa (Coetzee et al. 2000) and the availability of DNA sequence data for a collection of Armillaria spp. from southern Africa has provided the justification to reconsider the taxonomy of the three groups of isolates described from Zimbabwe. Since South Africa is a close neighbour of Zimbabwe, it was hypothesized that species composition in these two countries would be similar. A major limitation, however, in the classification of Armillaria in Zimbabwe is the rare occurrence of fruiting bodies (Swift 1968, Mwenje \& Ride 1996). Although basidiocarps have been encountered in the wild (Swift 1968, Mwenje \& Ride 1996), they are scarce, especially in years of low rainfall. Furthermore, the African taxa were previously shown to have a homothallic system (Abomo-Ndongo, Mohammed \& Guillaumin 1997), making sexual compatibility tests with tester strains impossible. As a result of these problems, we were prompted to use a DNA-based identification procedure to identify isolates from Zimbabwe. The aim of this study was, therefore, to consider the identity of isolates residing in the three groups previously identified in Zimbabwe. This was achieved by comparing their restriction fragment length polymorphism (RFLP) and nucleotide sequences of the intergenic spacer region one (IGS-1) region of the rRNA operon with one another and with sequences published by Coetzee et al. (2000).

\section{MATERIALS AND METHODS}

\section{Origin of isolates}

The identity and geographical origin of the isolates used in this study are given in Table 1. The six Zimbabwean isolates were chosen specifically to represent equal numbers of the three groups previously defined based on their morphological and biochemical characteristics (Mwenje \& Ride 1996). The Zimbabwean isolates are maintained in the Armillaria culture collection at the National University of Science and Technology in Bulawayo, Zimbabwe as well as the Forestry and Agricultural Biotechnology Institute (FABI), University of Pretoria, South Africa. Two Armillaria isolates from South Africa representing $A$. fuscipes were from the culture collection (CMW) of the FABI. The Armillaria isolates from South Africa were previously identified based on their basidiocarp morphology as well as their IGS-1 sequences and RFLP profiles. Isolates were maintained on $2 \%$ malt extract agar (MEA) slants and stored at $4{ }^{\circ} \mathrm{C}$. 


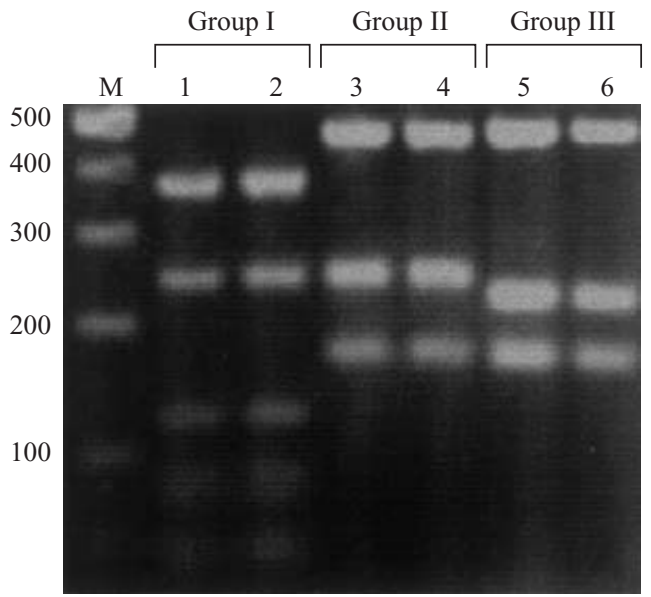

Fig. 1. A $3 \%$ agarose gel showing $A l u \mathrm{I}$ restriction fragments for Armillaria isolates used in this study. Lanes 1-6 show profiles for isolates CMW10165 (1), CMW04874 (2), CMW4455 (3), CMW4456 (4), CMW10115 (5) and CMW10116 (6). Lanes labelled with $\mathrm{M}$ indicates a $100 \mathrm{bp}$ molecular marker with band sizes in base pairs.

\section{Mycelium production and DNA preparation}

Cultures were grown in the dark under stationary conditions at $26^{\circ}$ in $250 \mathrm{ml}$ conical flasks containing $50 \mathrm{ml}$ liquid MY medium (3\% malt extract and $0.3 \%$ yeast extract). Mycelium was harvested after $3 \mathrm{wk}$ by filtration using Whatman no. 1 filter paper. The mycelium was freeze-dried and ground to a fine powder. DNA extractions from the powdered mycelium were achieved using the protocols of O'Donnell, Cigelnik \& Nirenberg (1998). The DNA pellets were rehydrated in $50 \mu \mathrm{l}$ of $\mathrm{dd}_{2} \mathrm{O}$ and stored at $-20^{\circ}$ until further use.

\section{Polymerase Chain Reaction (PCR) and RFLP analyses PCR}

The first intergenic spacer region (IGS-1) between the $3^{\prime}$ end of the large subunit (LSU) ribosomal RNA (rRNA) gene and the $5^{\prime}$ end of the 5S gene of Armillaria isolates was amplified using PCR. Amplicons were obtained with primer pair P-1 (Hsiau 1996) and 5S-2B (5'-CAC CGC ATC CCG TCT GAT CTG CG-3') as used by Coetzee et al. (2000) for amplification of Armillaria isolates from South Africa. The PCR reaction mixture included Taq polymerase (1.75 U) (Roche Diagnostics, Randburg), PCR buffer with $\mathrm{MgCl}_{2}$ supplied by the manufacturer, additional $\mathrm{MgCl}_{2}$ $(0.25 \mathrm{~mm})$, dNTPs $(1 \mathrm{~mm})$, primers $(0.01 \mu \mathrm{M}$ of each), and approximately $80 \mathrm{ng}$ of template DNA. PCR conditions were an initial denaturation at $94^{\circ}$ for $3 \mathrm{~min}$ followed by 35 cycles of denaturation $\left(30 \mathrm{~s}, 94^{\circ}\right)$, primer annealing $\left(30 \mathrm{~s}, 58^{\circ}\right)$, and elongation $\left(1 \mathrm{~min}, 72^{\circ}\right)$. A final step of $7 \mathrm{~min}$ at $72{ }^{\circ} \mathrm{C}$ was allowed for complete elongation of the amplicons. PCR products were electrophoresed on an ethidium bromide stained agarose gel $(1 \%)$ and visualized under uv illumination.

\section{RFLP}

IGS-1 amplicons obtained for the isolates from Zimbabwe were digested without prior purification as described by Harrington \& Wingfield (1995). Restriction profiles were obtained by digesting $18 \mu$ of the PCR product with the restriction endonuclease $A l u \mathrm{I}(20 \mathrm{U})$ for 5-7 h at $37^{\circ}$. The resulting PCR-RFLP fragments were separated on a $3 \%$ agarose gel stained with ethidium bromide and visualized under uv illumination. Fragments smaller than 100 bp (base pairs) were not considered due to their low visibility. RFLP fragment sizes were determined and compared with those previously published for African Armillaria species (Coetzee et al. 2000).

\section{DNA sequencing}

IGS-1 sequences for six Armillaria isolates representing the three Armillaria groups from Zimbabwe (Table 1) were determined using an ABI PRISM ${ }^{\mathrm{TM}} 377$ automated DNA sequencer. Sequence reactions were carried out using an ABI PRISM ${ }^{\mathrm{TM}}$ Dye Terminator Cycle Sequencing Ready Reaction Kit with AmpliTaq ${ }^{\circledR}$ DNA polymerase FS (Applied Biosystems, Johannesburg) according to the specification of the manufacturers. The IGS-1 region was sequenced in both directions using primers $\mathrm{P}-1,5 \mathrm{~S}-2 \mathrm{~B}, \mathrm{MCP}-2, \mathrm{MCP}-2 \mathrm{R}$, MCP-3, MCP-3R, 5S-3MC, 5S-3MCR, MCP-2A, MCP2AR, 5S-5MC, and 5S-5MCR (Coetzee et al. 2000).

\section{Sequence analyses}

Sequence data obtained for the six Armillaria isolates from Zimbabwe were aligned with alignments of Coetzee et al. (2000) available in TreeBase (matrix number: M859, study number: S566). Sequence alignments in poorly aligned regions, resulting from large indels, were manually optimized. Indels of two or more bases were treated as a single evolutionary event by a multi state coding system. The relationships between the isolates were determined by distance analysis in PAUP* version 4 (Swofford 1998) using mean character differences to accommodate coded indels. Trees were constructed using the Neighbour-Joining tree building algorithm (Saitou \& Nei 1987). Outgroups were not available for the data set, and trees were therefore rooted to midpoint. Support for the differentiation between Group II and Group III isolates was obtained by using Group I as the outgroup in bootstrap analysis. The sequence matrix and neighbourjoining tree generated in this study has been deposited in TreeBASE (study accession no. S840, matrix accession no. M1357).

\section{RESULTS}

\section{Amplification of IGS-1 and PCR-RFLPs}

PCR amplication of the IGS-1 region of Armillaria isolates resulted in amplicons of different sizes. Isolates 


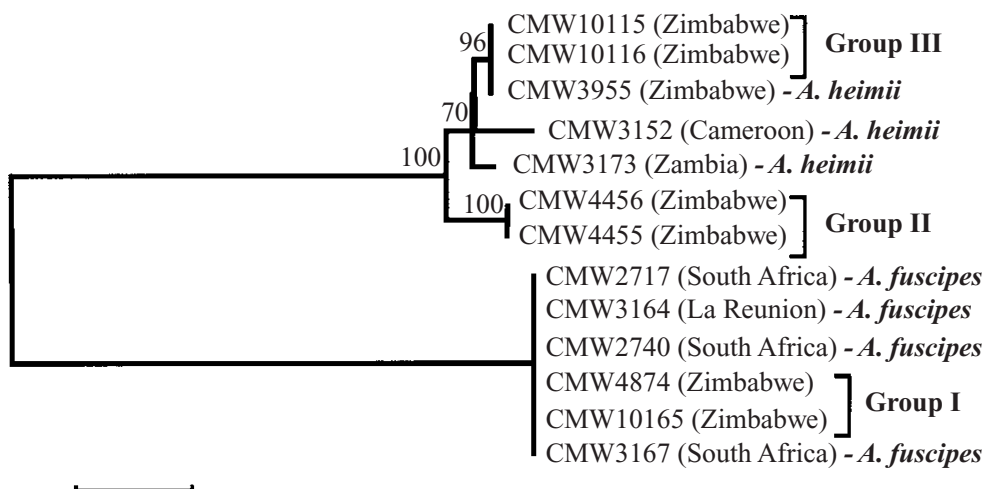

0.02

Fig. 2. Phylogram generated with the neigbour-joining tree building algorithm in PAUP*. Bar $=$ total nucleotide differences between taxa. Bootstrap values $(\%)$ are indicated above the branches.

representing Zimbabwean Group I (CMW10165 and CMW04874) gave a PCR fragment approximately 1200 bp in size. Group II (CMW4455 and CMW4456) and Group III (CMW10115 and CMW10116) isolates resulted in an amplified fragment size of approximately $900 \mathrm{bp}$.

RFLP profiles obtained after digestion of amplicons with the restriction enzyme Alu1 differed for all three of the previously defined Zimbabwean groups of isolates (Fig. 1). The two isolates chosen to represent Group I (CMW10165 and CMW4874) had similar RFLP patterns with fragments of approximately 380, 255 and 130 bp. Isolates representing Group II exhibited a distinct pattern with fragment sizes of approximately 480 , 255 and $175 \mathrm{bp}$. Group III isolates had an RFLP pattern with fragment sizes of approximately 480, 230 and 175 bp. No differences were observed in RFLP profiles for isolates within the same group and groups could thus be easily separated using this technique.

\section{DNA sequence analysis}

The IGS-1 data set included a total of 1191 characters after alignment with inclusion of gaps. Forty-eight indels were replaced with multi-state characters yielding a total of 715 characters that were used in a distance analysis. The absolute lengths of the IGS-1 sequences determined for the isolates from Zimbabwe were compared with the aligned sequences from Coetzee et al. (2000) after exclusion of 50 characters from the 3 ' end of the IGS-1 sequence matrix published by Coetzee et al. (2000). In this study the IGS-1 region sequenced for isolates of Group I (CMW10165 and CMW4874) was the same as that for isolates from South Africa (CMW2717 and CMW2740 and CMW3167) and La Reunion (CMW3164) and ranged from 1041 to 1044 bp. Isolates representing Zimbabwean Group II (CMW4456 and CMW4455), Group III (CMW10115 and CMW10116) and a previously sequenced Zimbabwean isolate CMW3955 (Coetzee et al. 2000) had an absolute length of $832 \mathrm{bp}$. Isolates from Cameroon and Zambia had absolute lengths of 816 and $803 \mathrm{bp}$, respectively.
DNA sequence analysis using the neighbour-joining analysis, grouped isolates into three major clusters that were consistent with those previously defined based on biochemical and morphological characteristics (Fig. 2). Armillaria isolates belonging to Group I grouped with $A$. fuscipes from South Africa (CMW2717 and CMW2740 and CMW3167) and La Reunion (CMW3164). Group II isolates (CMW4455 and CMW4456) grouped together and were separate from those representing Group III and these were not close to any other previously named species of Armillaria. Isolates from Zambia (CMW3173), Cameroon (CMW3152) and Zimbabwe (CMW3955) for which sequence data were available grouped with isolates of Group III (CMW10115 and CMW10116) (Fig. 2). Of these isolates, the previously sequenced Zambabwean isolate (Coetzee et al. 2000) was more closely related to the Group III isolates than to the isolate from Cameroon, previously thought to represent $A$. heimii.

\section{DISCUSSION}

This study confirms previous investigations (Swift 1968, 1972, Mwenje \& Ride 1996) in which Armillaria isolates from Zimbabwe were shown to represent more than one taxon. In addition, we have shown that the three groups, defined based on isozyme differences by Mwenje \& Ride (1996), can also be clearly separated on the basis of RFLP and DNA sequence differences. With these additional data, we believe that there is sufficient evidence to accept that the three groups represent distinct species of Armillaria. Of these, one group appears to represent $A$. fuscipes, one is close to what is thought to be $A$. heimii and one represents an undescribed species.

Group I isolates from Zimbabwe were identified as A. fuscipes based on their IGS-1 DNA sequence similarity with this species. The fact that this species is reflected in one of the three groups of Armillaria defined by Mwenje \& Ride (1996) is not surprising, since this species was recently described from South African forest plantations (Coetzee et al. 2000). A. fuscipes was 
first described by Petch (1909) from Sri Lanka and was thought to be introduced from West Africa (Pegler 1986). Pegler (1986), as well as Kile \& Watling (1988), considered $A$. fuscipes and $A$. heimii to be conspecific and the name $A$. heimii has been used by various authors for the African taxon. Coetzee et al. (2000), however, showed that there is a clear difference at the molecular and morphological level between $A$. fuscipes and $A$. heimii and that they should be treated as separate taxa. The fact that isolates previously thought to represent A. heimii (Mwenje \& Ride 1997) are most likely $A$. fuscipes, suggests that the latter species is the more widely distributed.

Armillaria isolates representing Group I and now recognized as $A$. fuscipes, have been found in forest plantations and fruit tree orchards as well as in indigenous woodlands in Zimbabwe (Mwenje \& Ride 1996, Mwenje et al. 1998). Group III isolates have the widest distribution and this fungus is thought to be the most pathogenic (Mwenje et al. 1998). This suggests that $A$. fuscipes is not the most important pathogen amongst Armillaria spp. in Zimbabwe.

IGS-1 DNA sequence analyses of isolates representing Zimbabwean groups II and III revealed a high number of differences in the presence of indels between the two groups. Mwenje \& Ride (1996) indicated that groups II and III can be separated based on their cultural and biological characterstics as well the as morphology of in vitro produced basidiocarps. Results obtained from RFLP and IGS-1 DNA sequence data analyses, in the present study, support the separation of Group II and III isolates and therefore, support those of Mwenje \& Ride (1996). The differences found between the groups II and III from Zimbabwe, by Mwenje \& Ride (1996) and in this study, suggest that they could represent two distinct species.

In this study, isolates of Armillaria representing Group III formed a monophyletic group with isolates from Cameroon, Zambia and Zimbabwe, thought to represent $A$. heimii (Coetzee et al. 2000). Basidiomes of Armillaria spp. are rare in Zimbabwe and only those linked to Group III were previously found and described in detail from this country (Mwenje \& Ride 1996). The morphology of these fruit bodies, however, differed from $A$. heimii in all characteristics (Mwenje \& Ride 1996) and also from those of $A$. fuscipes described in South Africa (Coetzee et al. 2000). A possible explanation for this contradiction is that cultures that have been treated as $A$. heimii, do not reflect this species. Resolution of this question will be difficult as it will require collections of isolates from fruit bodies in the area where $A$. heimii was first described.

Isolates representing Group II are significantly different to $A$. heimii based on IGS-1 sequence data. Identification of isolates residing in this group is currently not possible. Since the onset of studies on $\mathrm{Ar}$ millaria in Zimbabwe in 1989, over 60 isolates of this fungus have been collected in native forests and in plantations (unpublished data). Of particular interest is the fact that only two of these belong to Group II. These collections were primarily from diseased trees and support our view that the fungus is relatively unimportant as a pathogen. It is hoped that in the future, basidiocarps representing Group II isolates will be found so that this fungus can be provided with a name.

\section{ACKNOWLEDGEMENTS}

We thank the members of the Tree Pathology Co-operative Programme (TPCP), the Mellon Foundation, the National Research Foundation (NRF) and the THRIP initiative of the Department of Trade and Industry (DTI) South Africa as well as UNESCO-ANSTI and the Southern African Regional Co-operation in Biochemistry, Molecular Biology and Biotechnology (SARBIO) for financial support. We also acknowledge efforts of Julia A. Hasler (SARBIO Project Coordinator) to promote research collaboration in Southern Africa and without which the senior author would not have been able to undertake this study.

\section{REFERENCES}

Abomo-Ndongo, S. \& Guilaumin, J.-J. (1997) Somatic compatibility among African Armillaria isolates. European Journal of Forest Pathology 27: 201-206.

Abomo-Ndongo, S., Mohammed, C. \& Guillaumin, J.-J. (1997) Sexual behaviour of Armillaria heimii and A. mellea isolates from Africa. European Journal of Forest Pathology 27: 207-224.

Anderson, J. B. (1986) Biological species of Armillaria in North America: redesignation of groups IV and VIII and enumeration of voucher strains for other groups. Mycologia 78: 837-839.

Anderson, J. B. \& Ullrich, R. C. (1979) Biological species of Armillaria in North America. Mycologia 71: 402-414.

Chillali, M., Idder-Ighili, H., Guillaumin, J.-J., Mohammed, C. \& Botton, B. (1997) Species delimitation in the African Armillaria complex by analysis of the ribosomal DNA spacers. Journal of General and Applied Microbiology 43: 23-29.

Coetzee, M. P. A., Wingfield, B. D., Coutinho, T. A. \& Wingfield, M. J. (2000) Identification of the causal agent of Armillaria root rot of Pinus species in South Africa. Mycologia 92: 777-785.

Harrington, T. C. \& Wingfield, B. D. (1995) A PCR based identification method for species of Armillaria. Mycologia 87: 280-288.

Hsiau, P. T. W. (1996) The taxonomy and phylogeny of the mycangial fungi from Dendroctonus brevicomis and D. frontalis (Coleoptera: Scolytidae). PhD Thesis. Iowa State University. 92 p.

Kile, G. A. \& Watling, R. (1981) An expanded concept of Armillaria luteobubalina. Transactions of the British Mycological Society 77: 75-83.

Kile, G. A. \& Watling, R. (1983) Armillaria species for SouthEastern Australia. Transactions of the British Mycological Society 81: 129-140

Kile, G. A. \& Watling, R. (1988) Identification and occurrence of Australian Armillaria species, including A. pallidula sp. nov. and comparative studies between them and non-Australian tropical and Indian Armillaria. Transactions of the British Mycological Society 91: 305-315.

Korhonen, K. (1978) Interfertility and clonal size in the Armillaria mellea complex. Karstenia 18: 31-42.

Mohammed, C., Guillaumin, J.-J., Botton, B. \& Intini, M. (1994) Species of Armillaria in tropical Africa. In Proceedings of the 8th International Conference on Root and Butt Rots IUFRO Working Party S750.07 (M. Johansson \& J. Stenlid, eds): 402-410. Swedish University of Agricultural Sciences, Uppsala, Sweden.

Mwenje, E. \& Ride, J. P. (1996) Morphological and biochemical characterisation of Armillaria isolates from Zimbabwe. Plant Pathology 45: 1031-1051. 
Mwenje, E. \& Ride, J. P. (1997) The use of pectic enzymes in the characterisation of Armillaria isolates in Africa. Plant Pathology 46: 341-354.

Mwenje, E., Ride, J. P. \& Pearce, R. B. (1998) Distribution of Zimbabwean Armillaria groups and their pathogenicity on cassava. Plant Pathology 47: 623-634.

O’Donnell, K., Cigelnik, E. \& Nirenberg, H. I. (1998) Molecular systematics and phylogeography of the Gibberella fujikuroi species complex. Mycologia 90: 465-493.

Ota, Y., Matsushita, N., Nagasawa, E., Terashita, T., Fukuda, K. \& Suzuki, K. (1998) Biological species of Armillaria in Japan. Plant Disease 82: 537-543.

Pegler, D. N. (1977) A Preliminary Agaric Flora of East Africa. [Kew Bulletin Additional Series No. 6.] HMSO, London.

Pegler, D. N. (1986) Agaric Flora of Sri Lanka (Armillaria). [Kew Bulletin Additional Series No. 12.] HMSO, London.

Pegler, D. N. (2000) Taxonomy, nomenclature and description of Armillaria. In Armillaria Root Rot: biology and control of honey fungus (R. T. V. Fox, ed.): 81-93. Intercept, Andover.

Petch, T. (1909) New Ceylon fungi. Annuals of the Royal Botanical Garden Peradeniya 4: 299-307.
Podger, F. D., Kile, G. A., Watling, R. \& Fryer, J. (1978) Spread and effect of Armillaria luteobubalina sp. nov. in an Australian Eucalyptus regnans plantation. Transactions of the British Mycological Society 71: 77-87.

Saitou, N. \& Nei, M. (1987) The neighbour-joining method: A new method for reconstructing phylogenetic trees. Molecular Biology and Evolution 4: 406-425.

Swift, M. J. (1968) Inhibition of rhizomorph development by Armillaria mellea in Rhodesian forest soils. Transactions of the British Mycological Society 51 : 241-247.

Swift, M. J. (1972) The ecology of Armillaria mellea (Vahl ex Fries) in the indigenous and exotic woodlands of Rhodesia. Forestry 45 : $67-86$.

Swofford, D. L. (1998) PAUP*: Phylogenetic Analysis Using Parsimony (*and Other Methods). Version 4. Sinauer Associates, Sunderland, Massachusetts.

Volk, T. J. \& Burdsall, H. H. (1995) A nomenclatural study of Armillaria and Armillariella species. [Synopsis Fungorum No. 8.] Fungiflora, Oslo.

Corresponding Editor: N. Hallenberg 